\title{
Analysis of Communication and Mathematical Abstraction Ability of Junior High School Students' using Student Activity Sheets Based on Model of Learning Mean - Ends Analysis
}

\author{
I. Dewi ${ }^{1}$, N. Siregar ${ }^{2}$ and A.Andriani ${ }^{3}$,A.Ritonga ${ }^{4}$ \\ \{dewi_lubis62@yahoo.co.id\} \\ Department of Mathematic, UniversitasNegeriMedan, Willem Iskandar, Medan, Indonesia ${ }^{1,2,3,4}$
}

\begin{abstract}
Using Student Activity Sheets (SAS) in learning is one of the teacher's efforts to provide scaffolding to students. This paper is a limited trial in using student activity sheets based on Mean-Ends Analysis (MEA) learning models in the context of Malay culture.The purpose of this study is to analyze the communication and mathematical abstractions ability students' which using SAS in mathematics learning. The study was conducted at a junior high school in Perbaungan, North Sumatra. Subjects in the study were 7 th graders. Data were analyzed using descriptive analysis obtained from LAS which worked by students in groups. The results showed mathematical communication ability were in good category, while the ability of students' mathematical abstraction still needed improvement. Thus the student activity sheet based on the MEA learning model can be used as an alternative to improve students' mathematical communication skills
\end{abstract}

Keywords: Communication and mathematical abstraction.

\section{Introduction}

Communication skills and mathematical abstractions of students are important in mathematics learning. Through communication students can express their mathematical ideas clearly, and also through communication in mathematics learning the teacher can detect what students have and have not understood. Experts argue that mathematical communication is a window to human activity (Dewi, 2009), this is because the activities of human cognition cannot be seen and heard but can be observed through their communication activities.

In addition to communication skills students' mathematical abtraction ability is also needed in mathematics learning. (Gray \& Tall, 2007) defines abstraction as the process of describing a situation and also the results of abstraction from the process. Abstraction can then be interpreted in many forms, as processes, traits, or concepts. (Ferarri, 2003) states that abstraction is a basic process in mathematics. Furthermore (Mitchelmore \& White, 2012) defines abstraction as a mental representation of a mathematical object, of course abstract mathematical objects only have the meaning of the system in which they are defined. Thus it can be concluded that abstraction in mathematics is seen as a mental representation or description of a situation into a form simpler known as symbols and rules in mathematics. 
Errors in reflecting mathematical objects will make it difficult for students to understand mathematics. Seeing the importance of communication skills and mathematical abstractions in learning, the school needs to improve the communication skills and mathematical abstractions of students in learning. But both of these abilities are still low. To improve communication skills and mathematical abstractions of students by entering both of these abilities into the learning objectives to be achieved. There are several things that can affect the achievement of a learning goal, such as the selection of models and methods used by the teacher in learning.

Teacher-centered learning requires learning media that can make students more actively explore their own mathematical abilities. One medium that can be used by teachers to explore communication skills and mathematical abstractions of students is the Student Activity Sheet (SAS). This is because SAS contains a set of basic activities that must be carried out by students to maximize their mathematical understanding. Worksheets are a scaffolding section that serves to guide students in the learning process and encourage students to become independent learners while collaborating with members of their group (Ling. 2011).

The main objectives of using worksheets are: 1) to guide students in developing conceptual frameworks of important topics that are difficult for students, and 2) to direct perseverance in learning difficult concepts. In addition to choosing media, of course the teacher also chooses the right learning model in learning (Barniol\& Zavala, 2016). In addition to using SAS the teacher must also choose the learning model that will be used to achieve the learning objectives. The selection of the right learning model is an attempt by the teacher to create a pleasant classroom atmosphere. The ideal teacher is able to choose the right task, encourage students to learn meaningfully, organize discourse to create a learning atmosphere and class situation analysis. In this study the learning model used is Mean Ends Analysis (MEA).

The Means Ends Analysis (MEA) learning model is a learning model of variation between problem solving methods and syntax that presents the material in a heuristic-based problem solving approach that is in the form of a series of questions that are instructions to help students solve their problems. Therefore, the MEA learning model can help students move towards the Vigotsky Proximal Development Zone (ZPD). Furthermore, the MEA learning principle is in accordance with Piaget's cognitive development theory which argues that learning is the process of assimilation and accommodation. The process of assimilation in MEA learning is based on material principles presented by heuristic and reality approaches, while the accommodation process in MEA learning is based on the principles of problem translation, documentary, and sharing of abilities. The purpose of this paper is to find out how mathematical communication skills and also mathematical abstractions of students in learning using student activity sheets that are associated with local cultural wisdom.

\section{Research methods}

This research is a descriptive qualitative study. The place of research was conducted in a junior high school in the town of Perbaungan. The research subjects were class VII students, amounting to 36 students.

To obtain the desired data, subjects were given LAS with integer material using the MEA learning model based on Malay culture. LAS is done in mutual cooperation groups. Furthermore, the results of student group work are analyzed and the teacher confirms the answers by asking students to present in front of the class then conducting interviews. This 
activity aimed to get in-depth to gather information about the causes of the difficulties or mistakes made by students. After collecting data from the interview, the data was analyzed descriptively.

\section{Research result and discussion}

The following is presented the results of data analysis about students' communication skills and mathematical abstractions.

\subsection{Students' mathematical communication abilities}

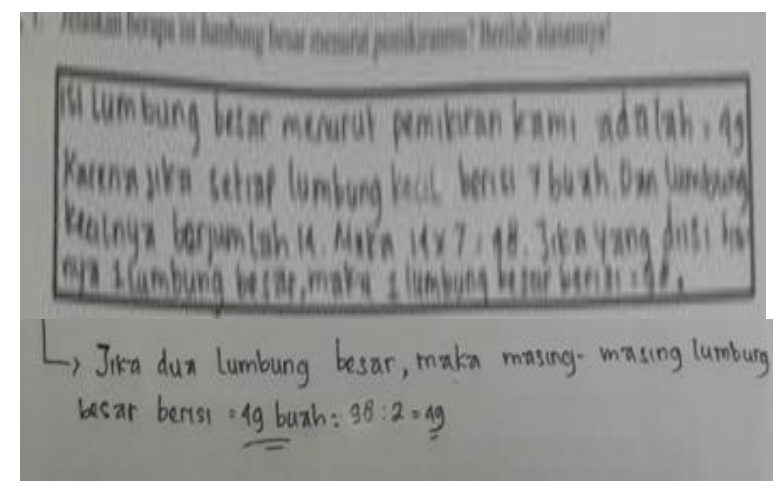

Problem: Explain how much is the contents of a large bam? Give reasons for your arswer.

Answer:

The number of contents of a large bam according to our thinking is 49 . Because if each small bam contains 7 pieces, and there are as many as 14 small barns, then the contents of a large bam are $14 \times 7=$ 98. If only 1 large bam is filled, then 1 large bam contains 98. If there are two large bams, then each large bam contains 49 pieces, namely $98: 2=49$.

Fig. 1. Student answer sheet from group 1

From figure 1 we can see that students have been able to communicate their thoughts clearly and correctly, and the arguments they give are also true. To check the communication skills of 
the teacher students ask for group 1 to explain the answers they gave. Students give answers verbally and the results are the same as the answers to the writing they have done. Then the teacher asks "If the doctor prescribes a drug with a dose of $3 \times 1$, what does it mean?" The student answers "means the medicine is taken one drug in the morning, one drug at noon, and one drug at night" The students' answers indicated that they could already explain what they were thinking about the concept of integer multiplication.

Answer sheet from group 2

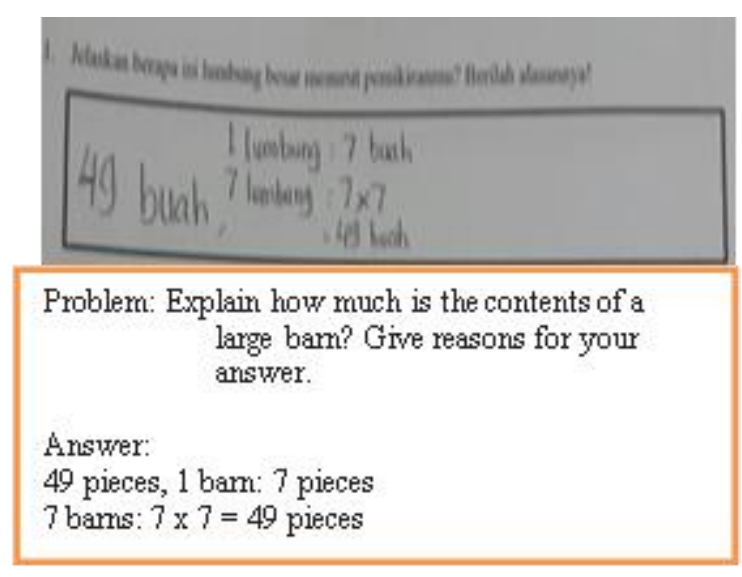

Fig. 2. Student answer sheet about mathematical communication from group 2

Group 2 answers are very brief. They wrote 1 barn 7 pieces, without explaining whether the barn was a small barn or large barn, even though the researchers understood what they meant was a small barn.

When interviewed with a question: explain how you got the answer 49? The student answers: "there are 7 small barns, each contains 7 stones, so the result is $7 \mathrm{x} 7$ ". Looking at the writing and verbal answers of group 2, it can be said that what students from group 2 write is also the same as what they say verbally. So the researchers concluded the students' answers were fixed. This means students have understood the concept of multiplication but they are difficult to explain what they think perfectly.

\subsection{Students' mathematical communication abilities}

Student Answer sheet from Group 1

From figure 3 we can see that even though it has been given a hint that $x$ is a symbol of the number of seeds (barn contents) a small barn is symbolized as $y$ but students still give different symbols from the instructions in the SAS. In this case students view the contents of a large barn with the number of congklak seeds in the form of numbers not in the form of mathematical symbols in general. So students still think concrete yet abstractly. This is what makes students difficult to perform mathematical symbols. 


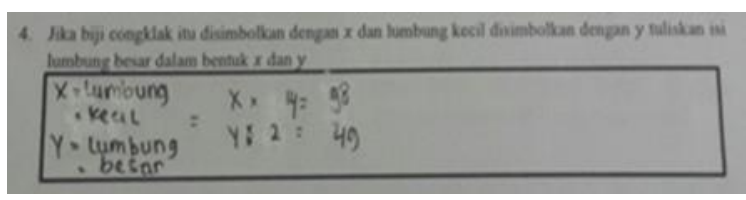

Problem: If the congklak seeds are symbolized by $x$ and the small bam is symbolized as $y$, write the contents of the large bam in the form of $x$ and $y$

Answer:

$$
\begin{aligned}
& x=\text { small bam } \\
& y=\text { big bam } \\
& x \times 14=98 \text { pieces } \\
& y: 2=49
\end{aligned}
$$

Fig. 3.Student answers about mathematical abstraction of students from group 1

Student Answer sheet from Group

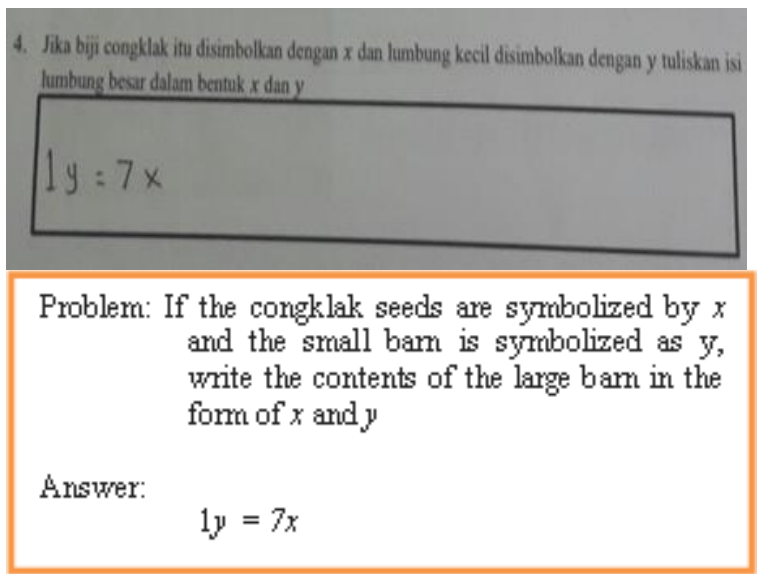

Fig. 4. Student answers about mathematical abstraction from group 2

The answer from group 2 is very short. When the researcher asks what is meant by the symbol $1 y=7 x$ ?, the student answers "that means in one large barn there are 7 times the congklak seeds". Then the researchers asked again, meaning that the contents of the large stomach contained 7 congklak seeds. Students answer "no, the contents of a large barn are 49 but we cannot write how the relationship $x$ and $y$ with a large barn. From the students' answers it can be concluded that students understand the multiplication concept but they have difficulty 
symbolizing the problem given in the form of variables. This means students still think concretely in solving mathematical problems.

According to (Dewi, 2018) in learning mathematics, abstraction is a fundamental processand have an important role in forming a concept. Through that process we can measure how far students have understood and built the concepts they have learned. From the two group answers, it can be seen that students have understood the concept of the problem given, but they have difficulty writing the mathematical symbols. This is because to carry out this symbolization process, analysis of concepts and mathematical representation is needed. According to (Husna, Johar, Hajidin, Mailizar, 2018) the main difficulty in learning algebra is how to use symbols of mathematics, because it emphasizes on the aspect of analysis as well as representation of mathematical concepts and ideas.

The importance of this symbolization is that it enforces a logically exact and complete formulation of a mathematical theorem. The symbols used in mathematics are universal languages that can be communicated correctly and clearly. This universal language makes mathematicians able to communicate with each other even though they come from different countries and languages. Likewise in mathematics learning, without using mathematical symbols the teacher cannot communicate their ideas and thoughts to his students precisely and clearly. Likewise students, they will have difficulty understanding mathematics if they do not understand the symbols used by the teacher in learning. Students will find it difficult to represent their mathematical understanding to others. The purpose of symbolization is to help thinkers provide a place to record thoughts and provide a means for thinkers to communicate with other thinkers (Draper, 2018).

\section{Conclusion}

In mathematics learning the student activity sheet can be used as one of the learning media to help students explore their mathematical abilities. So LAS can also be used to help improve students' communication skills and mathematical abstractions. Communication and abstraction problems are important things to improve because through communication the teacher can find out what the students have known or not.

One of the difficulties students have in communicating their mathematical understanding is because students still always think concretely. When students are asked to solve problems related to the ability of abstraction difficulties they encounter to do the symbolization correctly, even though students understand the mathematical concepts used to solve the problem. Because the ability of abstraction is a fundamental process that can help students build a concept, it is advisable for the teacher to always train students to provide mathematical problems related to abstraction skills.

\section{Acknoledgements}

The researchers thanked the Ministry of Research, Technology and Higher Education and Medan State University for providing funding to conduct this research. Furthermore, we also 
thank the Faculty of Mathematics and Natural Sciences, especially the 2018 AISTSSE committee, which has helped researchers publish the results of this study.

\section{References}

[1] Dewi, Izwita.: $\quad$ ProfilKomunikasiMatematikaMahasiswaCalon Guru ditinjaudariPerbedaanJenisKelamin.DisertasiTesistidakdipublikasikan.Program PascasarjanaSurabaya : Surabaya (2009)

[2] Dewi, I; Siregar, N; Andriani, A.:.The analysis of junior high school students' mathematical abstraction ability based on local cultural wisdom. Journal of Physics: Conf. Series 1088 (2018) 012076. IOP Publishing (2018)

[3] Barniol, P \&Zavala, G.:. A Tutorial Worksheet to Help Students Develop the Ability to Interpret the Dot Product as a Projection. Eurasia Journal of Mathematics, Science \& Technology Education. Vol. 12, No. 9: 2387-2398 (2016)

[4] Draper R. J.: Simbolizing and Communicating in Mathematics Classroom : Perspective on Discourse, Tool, and Instructional Design.Journal of Literacy Research. https://journals.sagepub.com/doi/pdf/10.1207/s15548430jlr3501_6. Diakses Oktober 2018 (2018)

[5] Ferrari, P.L.:Abstraction In Mathematics The Royal Society Publishing retrieved onApril 2018 from http://rstb.royalsocietypublishing.org/content/358/1435/1225(2003)

[6]Gray, E and Tall, D.: Abstraction as a Natural Process of Mental Compression MathematicsEduction ResearchJournal, 19(2) pp 23-40 (2007)

[7]Husna, M; Johar, R; Hajidin; Mailizar... Development of algebra test questio ns based on Bloom's Taxonomy.Journal of Physics: Conf. Series 1088(2018) 012043. IOP Publishing (2018)

[8] Ling, N. S.:. I Will Survive. Collaborative Learning in the PBL Classroom. 11: 20-22 (2011)

[9] Mitchelmore, M. C. \& White, P.:. Abstraction in Mathematics Learning.In Seel N. M. (eds) Encyclopedia of the Sciences of Learning. Springer, Boston, MA (2012) 